\title{
Evaluation of a rapid bacteriophage-based method for the detection of Mycobacterium tuberculosis in clinical samples
}

\author{
Ayman Mohamed Marei, ${ }^{1}+$ Eman Mohamed El-Behedy, ${ }^{1}$ Heba Ali Mohtady ${ }^{1}$ \\ and Afify Fahmy Afify ${ }^{2}$
}

Correspondence

Ayman Mohamed Marei

am177@le.ac.uk

Received 4 October 2002

Accepted 23 December 2002
Departments of Microbiology and Immunology ${ }^{1}$ and Internal Medicine ${ }^{2}$, Zagazig Faculty of Medicine, Egypt

Rapid, sensitive and low-cost methods are needed urgently for the detection of Mycobacterium tuberculosis in clinical samples, especially in developing countries. To this end, the clinical performance of FASTPlaqueTB ${ }^{\mathrm{TM}}$ (a bacteriophage-based method) has been studied in parallel with microscopy, standard microbiological culture and in-house IS6110-based PCR methods. A total of 64 samples, including 42 sputum samples and 22 urine samples, were tested in this study. The sensitivity, specificity and overall accuracy values for the FASTPlaqueTB assay relative to that of culture were respectively 76.5, 95 and $90 \%$. The corresponding values for the in-house IS6110based PCR assay were 88, 91 and $90 \%$ and, for Ziehl-Neelsen staining, were 59, 95 and $85 \%$. FASTPlaqueTB gave better clinical performance with urine samples than with sputum samples (sensitivity, specificity and overall accuracy were $100 \%$ with urine samples and 64, 93 and $84 \%$ with sputum samples). The $100 \%$ sensitivity of FASTPlaqueTB was higher than that of the corresponding values for PCR (67\%) with urine samples. In conclusion, FASTPlaqueTB proved to be sensitive, cheap relative to the PCR and rapid. It is able to detect $M$. tuberculosis in clinical samples within 1 day, reducing the time to diagnosis in comparison with culture.

\section{INTRODUCTION}

Tuberculosis (TB) is a serious public health problem and it is estimated by the World Health Organization (WHO) that approximately one-third of the world's population is infected with Mycobacterium tuberculosis, resulting every day in more than 23000 people developing active TB and about 5000 deaths (WHO, 2002). The disease is especially prevalent in developing countries, where it accounts for more than a quarter of all preventable adult deaths (Harries \& Maher, 1997). The failure to detect TB cases rapidly and accurately, shortages of resources for TB control programmes all over the developing world, the failure to ensure that patients complete therapy and the emergence of multi-drug-resistant strains of tubercle bacilli, in addition to the impact of HIV infection on the incidence of TB, have helped to make TB the leading global cause of death from infectious diseases (Dolin et al., 1993).

Currently, the only sure criterion for definite diagnosis of TB is the demonstration of the presence of tubercle bacillus in

tPresent address: Microbiology and Immunology Department, Leicester University, Leicester LE1 9HN, UK.

Abbreviations: LJ, Löwenstein-Jensen; TB, tuberculosis; ZN, ZiehlNeelsen. clinical specimens. This is based on traditional methods: the Ziehl-Neelsen (ZN) acid-fast stain and laboratory culture of M. tuberculosis on Löwenstein-Jensen (LJ) medium. However, ZN staining lacks specificity and sensitivity, whilst confirmation by culture requires several weeks (McNerney, 1996). Although new, more rapid diagnostic methods have been developed that are based either on liquid culture techniques such as BACTEC (Middlebrook et al., 1977) or on molecular techniques (Sandin, 1996), their expense plus the requirement for specialist personnel and equipment have limited their use in many routine diagnostic laboratories, especially in developing countries. Consequently, there is a need for rapid, sensitive, low-cost techniques that are suitable for routine use in the developing world.

The use of mycobacteriophage in studies of Mycobacterium has increased since their first identification over 50 years ago (Gardner \& Weiser, 1947). Recently, phages have been considered as an important tool for either identification or drug susceptibility testing of Mycobacterium species (McNerney et al., 1998).

FASTPlaque $\mathrm{TB}^{\mathrm{TM}}$ utilizes mycobacteriophage (viruses that specifically infect mycobacteria) to reflect the presence of viable $M$. tuberculosis within a specimen. The specimen is first decontaminated, to kill most bacteria other than the target 
mycobacteria. The target bacterial cells present in the treated specimen are rapidly infected by the target-specific bacteriophage, termed Actiphage, which is added to the decontaminated specimen. The resulting mixture is then treated with a virucidal solution (Virusol) that causes the destruction of all bacteriophage that have not infected host cells. After treatment with virucidal solution, the only bacteriophage that remain are those that are protected within viable target mycobacteria. These bacteriophage continue to replicate until new progeny phage are released as the cells lyse. These progeny bacteriophage are then amplified by the introduction of a non-pathogenic, rapidly growing cell host (Sensor cells). Progeny bacteriophage undergo rapid cycles of infection, replication and lysis, which are seen as clear areas (plaques) in a lawn of confluent growth of Sensor cells. The number of plaques generated from a given sample is related to the number of viable $M$. tuberculosis cells containing mycobacteriophage. If there are no target bacteria (i.e. viable M. tuberculosis cells) in the original sample, there will be no phage amplification and therefore no bacteriophage to detect as plaques at the end of the assay (BIOTEC Laboratories, 2000).

We aimed in this study to evaluate the clinical performance of the FASTPlaqueTB assay by comparing its results with those of ZN stain, culture and in-house PCR.

\section{METHODS}

Clinical specimens. We investigated clinical specimens submitted for diagnosis of mycobacterial disease from Zagazig University hospital from August to November 2001. The patient group are clinically suspected cases with persistent symptoms and with radiological abnormalities. Samples from patients under antituberculous treatment were not investigated.

Sample processing. Sputum and urine samples were included in this study. Three successive early morning sputum and urine samples (each $45 \mathrm{ml}$ ) were collected from each patient in $50 \mathrm{ml}$ sterile plastic containers. Decontamination of all samples was carried out using the $\mathrm{N}$-acetyl-L-cysteine (NALC)/NaOH method (Kent \& Kubica, 1985). NALC $(0.5 \%$, w/v; Sigma) was added to a $1: 1$ mixture of $4 \% \mathrm{NaOH}$ and $2.9 \%$ sodium citrate solution to prepare the decontamination solution. An equal volume of the NALC/ $\mathrm{NaOH}$ decontamination solution was added to each sample in a sterile $50 \mathrm{ml}$ conical centrifuge tube. The samples were briefly vortexed (not more than $30 \mathrm{~s}$ ) and then incubated for $15 \mathrm{~min}$ at room temperature. The samples were diluted with phosphate buffer $(0.067 \mathrm{M}$ phosphate buffer, $\mathrm{pH} 6.8)$ up to the $45 \mathrm{ml}$ mark on the centrifuge tube and then centrifuged for $20 \mathrm{~min}$ at a minimum of $2000 \mathrm{~g}$. The supernatant was gently poured off and the sediment was resuspended in $2 \mathrm{ml}$ distilled water. Two hundred $\mu \mathrm{l}$ of each resuspended sediment was removed and kept at $2-8{ }^{\circ} \mathrm{C}$ for subsequent PCR testing. The remaining sediment was used for acidfast staining, FASTPlaqueTB and culture on LJ medium.

Microscopy. Smears were stained with the $\mathrm{ZN}$ technique (Kent \& Kubica, 1985). The resuspended deposit from each processed sample was used for smear preparation by spreading a drop over the middle two-thirds of a glass slide. After drying, smears were stained by $\mathrm{ZN}$ acidfast stain (30 g basic fuchsin, $50 \mathrm{~g}$ phenol crystals, $200 \mathrm{ml} 95 \%$ ethanol and double-distilled water to $1 \mathrm{l}$ ) and decolourized by a decolourizing agent ( $\mathrm{HCl}$ and ethanol at final concentrations of 3 and $95 \%)$.
Culture. Aliquots of $200 \mu \mathrm{l}$ sediment were inoculated onto slants of LJ medium.

FASTPlaqueTB. The FASTPlaque TB assay (BIOTEC Laboratories) was performed according to the manufacturer's instructions supplied with the kit. Fifteen millilitres FASTPlaqueTB medium Plus (FPTB) was added to the remaining resuspended sample and centrifuged for $20 \mathrm{~min}$ at a minimum of $2000 \mathrm{~g}$. The supernatant was gently poured off and the resultant pellet was resuspended in FPTB. Aseptically, $1 \mathrm{ml}$ suspension was transferred to a reaction vessel and incubated overnight at $37^{\circ} \mathrm{C}$. Control tubes containing $1 \mathrm{ml} \mathrm{FPTB}$ and a tube containing positivecontrol Sensor cells were included with each batch processed. One hundred microlitres of Actiphage was added to each sample and control, mixed and incubated at $37^{\circ} \mathrm{C}$ for $60 \mathrm{~min}$. After the incubation, $0.1 \mathrm{ml}$ Virusol solution was added to each sample and control. The content was allowed to mix by inverting and rolling the reaction vessel and the reaction vessel was then allowed to stand at room temperature for $5 \mathrm{~min}$. Five millilitres FPTB was added to the vessel and mixed by inverting the reaction vessel once. One millilitre Sensor cells was added to each vessel. Molten FPTB agar was prepared and cooled to approximately $55^{\circ} \mathrm{C}$ and $5 \mathrm{ml}$ was added to an empty sterile Petri dish for each specimen or control. The entire content of the reaction vessel was poured into the $90 \mathrm{~mm}$ Petri dish and the content was mixed well by swirling in both directions. The dish was allowed to set before incubation overnight at $37^{\circ} \mathrm{C}$. Plates were then examined for lysis; the presence of plaques indicates the presence of viable M. tuberculosis in the samples. The negative control should give 10 plaques or fewer and the positive control between 20 and 300 plaques.

PCR for detecting $\boldsymbol{M}$. tuberculosis DNA. DNA was extracted from sputum samples according to Kocagoz et al. (1993). An aliquot of $500 \mu \mathrm{l}$ resuspended deposit was transferred to a sterile $1.5 \mathrm{ml}$ Eppendorf tube and centrifuged at $12600 \mathrm{~g}$ at $4{ }^{\circ} \mathrm{C}$ for $5 \mathrm{~min}$. The supernatant was discarded and the pellet was resuspended in $1 \mathrm{ml}$ TET buffer $(10 \mathrm{mM}$ Tris/HCl, $1 \mathrm{mM}$ EDTA and $1 \%$ Triton $\mathrm{X}-100, \mathrm{pH} 8$ ), mixed well, incubated at $4{ }^{\circ} \mathrm{C}$ for $5 \mathrm{~min}$ and centrifuged as above. The supernatant was discarded and the pellet was resuspended in $1 \mathrm{ml}$ TET buffer. The lysis process was repeated twice and the pellet was then washed in $1 \mathrm{ml}$ TE buffer (10 mM Tris/ $\mathrm{HCl}, 1 \mathrm{mM}$ EDTA, $\mathrm{pH} 8.0)$ and centrifuged again as above. The washed pellet was resuspended in $470 \mu \mathrm{TE}$ buffer containing $10 \mathrm{mg}$ lysozyme $\mathrm{ml}^{-1}$, mixed well and removed to a $0.5 \mathrm{ml}$ centrifuge tube, which was incubated at $4{ }^{\circ} \mathrm{C}$ for $30 \mathrm{~min}$. Twenty-five microlitres $10 \%$ SDS and $5 \mu 110 \mathrm{mg}$ proteinase $\mathrm{K} \mathrm{ml}^{-1}$ were added to give final concentrations of $0.5 \%$ and $100 \mathrm{mg} \mathrm{ml}^{-1}$ and the tube was incubated at $56{ }^{\circ} \mathrm{C}$ for $5 \mathrm{~h}$. The tube was heated at $95^{\circ} \mathrm{C}$ for $10 \mathrm{~min}$ to inactivate proteinase $\mathrm{K}$ and cooled at $4{ }^{\circ} \mathrm{C}$ for not more than $18 \mathrm{~h}$. The sample was centrifuged at $12600 \mathrm{~g}$ for $5 \mathrm{~min}$ and the supernatant was removed to a new $1.5 \mathrm{ml}$ Eppendorf tube. The supernatant was gently extracted twice with an equal volume of phenol, twice with an equal volume of phenol/chloroform $(1: 1)$ and once with an equal volume of chloroform. One-tenth volume of $3 \mathrm{M}$ sodium acetate ( $\mathrm{pH} 5 \cdot 2$ ) was added to the extracted supernatant ( 300 or $400 \mu \mathrm{l}$ ) and mixed well. DNA from the extracted supernatant was precipitated with 2 vols ice-cold ethanol by standing at $-20^{\circ} \mathrm{C}$ for $1 \mathrm{~h}$ and centrifuging at $12600 \mathrm{~g}$ at $4{ }^{\circ} \mathrm{C}$ for $20 \mathrm{~min}$. The precipitated DNA pellet was rinsed with $1 \mathrm{ml} 70 \%$ ethanol and centrifuged at $12600 \mathrm{~g}$ at $4{ }^{\circ} \mathrm{C}$ for $10 \mathrm{~min}$. The supernatant was gently poured off and the DNA pellet was dried under vacuum and sometimes at room temperature by evaporation to allow gentle removal of traces of ethanol. The DNA pellet was resuspended in $40 \mu \mathrm{l}$ TE buffer and stored at $-20{ }^{\circ} \mathrm{C}$ until being used in the PCR.

A 317 bp DNA segment specific for IS6110 of M. tuberculosis was amplified using a DNA Thermal Cycler (Perkin Elmer-Cetus) according to the method described by Clarridge et al. (1993).

The PCR products were detected by agarose gel electrophoresis according to the method described by Sambrook et al. (1989). The 
molecular sizes of all products were estimated and those showing a single band of $317 \mathrm{bp}$ were recorded as being positive for M. tuberculosis complex.

For the PCR positive control, parts of the decontaminated sputum and urine samples were divided into two equal $2 \mathrm{ml}$ microcentrifuge tubes. One was spiked with $M$. tuberculosis and the other was left untreated. These control samples were processed immediately for PCR and used as controls.

Definition of the 'gold standard'. A specimen was considered truly positive for M. tuberculosis when positive by culture. Specimens with discrepant results by PCR were retested by the same technique. Specimens positive by culture and negative by PCR were retested for inhibition using serial dilutions of the specimens.

\section{RESULTS}

A total of 64 samples was collected from patients suspected to have M. tuberculosis infection and processed by the $\mathrm{ZN}$ staining method, standard culture, FASTPlaqueTB and inhouse PCR assays to evaluate the clinical performance of the various assays in detecting $M$. tuberculosis. Forty-two were respiratory specimens and the remaining 22 were urine samples.

Of the 42 respiratory specimens, two samples were contaminated by other micro-organisms and another two gave non-interpretable results when tested by FASTPlaque TB assay. These were removed prior to analysis of the results.

Seventeen samples out of $60(28 \cdot 3 \%)$ were positive for $M$. tuberculosis by culture. Ten of the culture-positive samples were also smear-positive $(58 \cdot 8 \%)$. Two samples were posi- tive by acid-fast staining, but negative by culture; the two samples were urine samples and were considered unspecific positive results, because they were negative by both PCR and FASTPlaque TB assays.

Of the 17 FASTPlaqueTB-positive culture samples, 15 were also positive by in-house PCR $(88 \cdot 2 \%)$. Four samples were PCR-positive and negative by culture; two were truly positive, since they gave positive results by FASTPlaqueTB, and the other two positive in-house PCR samples were considered false positive, because they were negative by the three other assays (Table 1 ).

Of 15 samples found to be positive by FASTPlaqueTB assay, 13 samples were concomitantly positive by culture. The two positive FASTPlaqueTB samples that were missed by culture were identified as positive by PCR (Table 1).

Table 2 shows that PCR has better sensitivity ( $88 \%)$ than FASTPlaqueTB and ZN (59\%); however, the value of $91 \%$ for specificity was lower than the value of $95 \%$ for both FASTPlaque TB assay and ZN.

\section{Sensitivity of FASTPlaqueTB on sputum and urine samples}

The results of FASTPlaqueTB were compared with those of PCR in concordance with those of culture, and this comparison demonstrated that the performance of FASTPlaque TB was better with urine samples ( $100 \%$ sensitivity, specificity and overall accuracy for urine samples versus 64 , 93 and $84 \%$, respectively, for sputum; Table 2). Among the urine samples, there were four samples with discordantly

Table 1. Comparison of the results of ZN stain, FASTPlaqueTB and PCR assays with the results of culture in sputum and urine samples

\begin{tabular}{|c|c|c|c|c|c|}
\hline \multirow[t]{2}{*}{ Samples } & \multirow{2}{*}{$\begin{array}{c}\text { FASTPlaqueTB } \\
\text { result }\end{array}$} & \multicolumn{2}{|c|}{ Culture-positive } & \multicolumn{2}{|c|}{ Culture-negative } \\
\hline & & $\begin{array}{c}\text { PCR- } \\
\text { positive }\end{array}$ & $\begin{array}{c}\text { PCR- } \\
\text { negative }\end{array}$ & $\begin{array}{c}\text { PCR- } \\
\text { positive }\end{array}$ & $\begin{array}{c}\text { PCR- } \\
\text { negative }\end{array}$ \\
\hline \multicolumn{6}{|l|}{ All samples $(n=60)$} \\
\hline \multirow[t]{2}{*}{ All $(n=60)$} & + & 12 & 1 & 2 & 0 \\
\hline & - & 3 & 1 & 2 & 39 \\
\hline \multirow[t]{2}{*}{ ZN-positive $(n=12)$} & + & 10 & 0 & 0 & 0 \\
\hline & - & 0 & 0 & 0 & 2 \\
\hline \multirow[t]{2}{*}{ ZN-negative $(n=48)$} & + & 4 & 1 & 2 & 0 \\
\hline & - & 1 & 1 & 2 & 37 \\
\hline \multicolumn{6}{|l|}{ Sputum $(n=38)$} \\
\hline \multirow[t]{2}{*}{ ZN-positive $(n=6)$} & + & 6 & 0 & 0 & 0 \\
\hline & - & 0 & 0 & 0 & 0 \\
\hline \multirow[t]{2}{*}{ ZN-negative $(n=32)$} & + & 1 & 0 & 2 & 0 \\
\hline & - & 2 & 2 & 2 & 23 \\
\hline \multicolumn{6}{|l|}{ Urine $(n=22)$} \\
\hline \multirow[t]{2}{*}{ ZN-positive $(n=6)$} & + & 4 & 0 & 0 & 0 \\
\hline & - & 0 & 0 & 0 & 2 \\
\hline \multirow[t]{2}{*}{ ZN-negative $(n=16)$} & + & 0 & 2 & 0 & 0 \\
\hline & - & 0 & 0 & 0 & 14 \\
\hline
\end{tabular}


Table 2. Sensitivity, specificity and overall accuracy of ZN stain, FASTPlaqueTB and PCR assays compared with culture

Values are percentages.

\begin{tabular}{|lccc|}
\hline Specimens & Sensitivity & Specificity & Overall accuracy \\
\hline All $(\boldsymbol{n}=\mathbf{6 0})$ & & & \\
FASTPlaqueTB & $76 \cdot 5$ & 95 & 90 \\
PCR & 88 & 91 & 90 \\
ZN & 59 & 95 & 85 \\
Sputum $(\boldsymbol{n}=\mathbf{3 8})$ & & & \\
FASTPlaqueTB & 64 & 93 & 84 \\
PCR & 82 & 85 & 84 \\
ZN & $54 \cdot 5$ & 100 & 87 \\
Urine $(\boldsymbol{n}=\mathbf{2 2})$ & & & 100 \\
FASTPlaqueTB & 100 & 100 & 91 \\
PCR & 67 & 100 & 82 \\
ZN & 67 & $87 \cdot 5$ & \\
\hline
\end{tabular}

positive results, two of these were culture-positive and confirmed by FASTPlaqueTB but were negative by PCR with no inhibition of PCR, and the other two urine samples with discrepant results gave unspecific positive smear results, as M. tuberculosis could not be ruled out by culture, FASTPla$q u e \mathrm{~TB}$ or PCR.

\section{DISCUSSION}

TB is still considered a major public health problem and it has been estimated that more people are currently dying each year from TB than at any previous time in history. Rapid and accurate diagnosis is a main step in the control of pulmonary $\mathrm{TB}$. In low-income countries, there is a special need for cheap and simple diagnostic techniques.

Advances in the understanding of the structure and function of mycobacteriophages have led to their use as an important research tool in diagnosis and drug susceptibility tests for TB. It has been demonstrated that phage assays can be used to examine susceptibility of $M$. tuberculosis isolates to rifampicin and isoniazid (Wilson et al., 1997). Luciferase reporter phages have been constructed using D29 (Pearson et al., 1996), and specific detection of $M$. tuberculosis has been reported using an assay incorporating $p$-nitro- $\alpha$ acetylamino- $\beta$-hydroxy propiophenone (Riska et al., 1997). The data available on the D29 phage assay show significantly high sensitivity for detection of viable $M$. tuberculosis (McNerney et al., 1998). The sensitivity of the phage assay is higher than the sensitivity of fluorescent microscopy, which requires $10^{4}$ c.f.u. $\mathrm{ml}^{-1}$, and is 12 -fold higher than the sensitivity reported using luciferase reporter phage (Carriere et al., 1997), and is reported to be similar to the sensitivities of nucleic acid amplification techniques (Sandin, 1996). We therefore aimed in this study to assess the clinical performance of a novel, rapid, commercial bacteriophagebased technique (FASTPlaqueTB) in parallel with in-house IS6110-based PCR, ZN staining and culture.
This study showed specificities of $95 \%$ for both FASTPla$q u e \mathrm{~TB}$ and $\mathrm{ZN}$ stain and $91 \%$ for PCR. Sensitivity results of our in-house PCR according to culture were comparable with those reported in different studies using IS6110-based PCR (Brisson-Noel et al., 1991; Lalande et al., 1996; Schirm et al., 1995) and those using the Amplicor test, with sensitivity ranging from 67 to $87 \%$ (Moore \& Curry, 1995; Vuorinen et al., 1995). However, the specificity of our in-house PCR method (91\%) was lower in comparison with the former methods (96-100\%), but considerably higher than that found in other labs (Pfyffer, 1999). In this study, we used the enzymic digestion and phenol/chloroform extraction method. This method is labour-intensive, time-consuming and involves multiple steps. Extraction procedures employing multiple steps to purify DNA from respiratory samples appear to have lower rates of inhibition (Eisenach et al., 1990) compared with those with fewer steps (Forbes \& Hicks, 1993). Yuen et al. (1993) reported that inhibitors were found in $3 \cdot 2 \%$ of sputum samples in which DNA was extracted by digestion with lysozyme and lysing by heat and SDS solution, followed by extraction with phenol/chloroform and ethanol precipitation. Nolte et al. (1993) found that $10 \%$ of specimens were inhibitory to PCR when samples were centrifuged, lysed with detergent, heated and then centrifuged again. When DNA was extracted from inhibitory samples with phenol/chloroform, precipitated with ethanol and retested, inhibitors were removed in all cases.

In this study, ZN staining achieved sensitivity, specificity and overall accuracy of 59, 95 and $85 \%$. Kocagoz et al. (1993) recorded that sensitivity, specificity and positive and negative predictive values of $\mathrm{ZN}$ smear were respectively $68,100,100$ and $70 \%$. Similar results were reported by Querol et al. (1995), who found a microscopic sensitivity of $65 \%$ and specificity of $100 \%$. Also, Herrera \& Segovia (1996) recorded that, considering clinical diagnosis as the 'gold standard', the sensitivity, specificity and positive and negative predictive values for $\mathrm{ZN}$ smear were respectively $69,87,84$ and $74 \%$. We can therefore conclude that the results of previous studies agree with our result in that $\mathrm{ZN}$ staining showed low sensitivity but high specificity.

In this study, we also evaluated the performance of these assays with non-respiratory specimens (urine specimens). The sensitivity, specificity and overall accuracy of FASTPla$q u e \mathrm{~TB}$ with urine specimens compared with that of culture (all values $100 \%$ ) were higher than its sensitivity, specificity and overall accuracy with respiratory specimens (respectively 64, 93 and $84 \%$ ), and this can be explained either by high sample volume or by the decrease in viscosity of urine over sputum.

We conclude that the FASTPlaqueTB assay demonstrates satisfactory clinical performance in terms of sensitivity and specificity, especially with urine specimens. It offers the advantage of having a visible end-point, which allows a same-day result, and can replace the standard culture for $M$. tuberculosis. Also, it is a cheap technology in comparison with PCR [the cost is 20 EGP (US $\$ 4.30$ at current rates) for ZN, 60 
EGP (US\$13) for FASTPlaqueTB and 110 EGP (US\$23.80) for PCR] and would therefore be suitable for use by routine microbiology laboratories, especially in developing countries.

\section{REFERENCES}

BIOTEC Laboratories (2000). FASTPlaqueTB Instruction Manual. Ipswich, UK: BIOTEC Laboratories.

Brisson-Noel, A., Aznar, C., Chureau, C. \& 7 other authors (1991). Diagnosis of tuberculosis by DNA amplification in clinical practice evaluation. Lancet 338, 364-366.

Carriere, C., Riska, P. F., Zimhony, O., Kriakov, J., Bardarov, S., Burns, J., Chan, J. \& Jacobs, W. R., Jr (1997). Conditionally replicating luciferase reporter phages: improved sensitivity for rapid detection and assessment of drug susceptibility of Mycobacterium tuberculosis. J Clin Microbiol 35, 3232-3239.

Clarridge, J. E., III, Shawar, R. M., Shinnick, T. M. \& Plikaytis, B. B. (1993). Large-scale use of polymerase chain reaction for detection of Mycobacterium tuberculosis in a routine mycobacteriology laboratory. J Clin Microbiol 31, 2049-2056.

Dolin, P. J., Raviglione, M. C. \& Kochi, A. (1993). Estimates of future global tuberculosis morbidity and mortality. MMWR 42, 961-964.

Eisenach, K. D., Cave, M. D., Bates, J. H. \& Crawford, J. T. (1990). Polymerase chain reaction amplification of a repetitive DNA sequence specific for Mycobacterium tuberculosis. J Infect Dis 161, 977-981.

Forbes, B. A. \& Hicks, K. E. (1993). Direct detection of Mycobacterium tuberculosis in respiratory specimens in a clinical laboratory by polymerase chain reaction. J Clin Microbiol 31, 1688-1694.

Gardner, G. \& Weiser, R. (1947). A bacteriophage for Mycobacterium smegmatis. Proc Soc Exp Biol Med 66, 205-206.

Harries, A. \& Maher, D. (1997). TB. A Clinical Manual for South-East Asia. Geneva: World Health Organization.

Herrera, E. A. \& Segovia, M. (1996). Evaluation of mtp40 genomic fragment amplification for specific detection of Mycobacterium tuberculosis in clinical specimens. J Clin Microbiol 34, 1108-1113.

Kent, P. \& Kubica, G. (1985). Public Health Microbiology: a Guide for the Level III Laboratory. Atlanta: Centers for Disease Control.

Kocagoz, T., Yilmaz, E., Ozkara, S., Kocagoz, S., Hayran, M., Sachedeva, M. \& Chambers, H. F. (1993). Detection of Mycobacterium tuberculosis in sputum samples by polymerase chain reaction using a simplified procedure. J Clin Microbiol 31, 1435-1438.

Lalande, V., Doucet-Populaire, F., Chataigne, R., Ghnassia, C. \& Petit, C. (1996). Comparison of two decontamination methods for direct detection by PCR of Mycobacterium tuberculosis from smear-positive specimens. Abstract presented at the Cinquiemes Journee de Mycobacteriologie de Langue Francaise, Nice, France, 6-7 November 1996.

McNerney, R. (1996). Diagnosis: present difficulties and prospects for the future. Afr Health 19 (1), 22-23.

McNerney, R., Wilson, S. M., Sidhu, A. M., Harley, V. S., al Suwaidi, Z., Nye, P. M., Parish, T. \& Stoker, N. G. (1998). Inactivation of mycobacteriophage D29 using ferrous ammonium sulphate as a tool for the detection of viable Mycobacterium smegmatis and M. tuberculosis. Res Microbiol 149, 487-495.

Middlebrook, G., Reggiardo, Z. \& Tigertt, W. D. (1977). Automatable radiometric detection of growth of Mycobacterium tuberculosis in selective media. Am Rev Respir Dis 115, 1066-1069.

Moore, D. F. \& Curry, J. I. (1995). Detection and identification of Mycobacterium tuberculosis directly from sputum sediments by Amplicor PCR. J Clin Microbiol 33, 2686-2691.

Nolte, F. S., Metchock, B., McGowan, J. E., Jr, Edwards, A., Okwumabua, O., Thurmond, C., Mitchell, P. S., Plikaytis, B. \& Shinnick, T. (1993). Direct detection of Mycobacterium tuberculosis in sputum by polymerase chain reaction and DNA hybridization. J Clin Microbiol 31, $1777-1782$.

Pearson, R. E., Jurgensen, S., Sarkis, G. J., Hatfull, G. F. \& Jacobs, W. R., Jr (1996). Construction of D29 shuttle plasmids and luciferase reporter phages for detection of mycobacteria. Gene 183, 129-136.

Pfyffer, G. E. (1999). Nucleic acid amplification for mycobacterial diagnosis. J Infect 39, 21-26.

Querol, J. M., Farga, M. A., Granda, D., Gimeno, C. \& Garcia-de-Lomas, J. (1995). The utility of polymerase chain reaction (PCR) in the diagnosis of pulmonary tuberculosis. Chest 107, 1631-1635.

Riska, P. F., Jacobs, W. R., Jr, Bloom, B. R., McKitrick, J. \& Chan, J. (1997). Specific identification of Mycobacterium tuberculosis with the luciferase reporter mycobacteriophage: use of $p$-nitro- $\alpha$-acetylamino$\beta$-hydroxy propiophenone. J Clin Microbiol 35, 3225-3231.

Sambrook, J., Fritsch, E. \& Maniatis, T. (1989). Molecular Cloning: a Laboratory Manual, 2nd edn. Cold Spring Harbor, NY: Cold Spring Harbor Laboratory.

Sandin, R. L. (1996). Polymerase chain reaction and other amplification techniques in mycobacteriology. Clin Lab Med 16, 617-639.

Schirm, J., Oostendorp, L. A. \& Mulder, J. G. (1995). Comparison of Amplicor, in-house PCR, and conventional culture for detection of Mycobacterium tuberculosis in clinical samples. J Clin Microbiol 33, 3221-3224.

Vuorinen, P., Miettinen, A., Vuento, R. \& Hallstrom, O. (1995). Direct detection of Mycobacterium tuberculosis complex in respiratory specimens by Gen-Probe Amplified Mycobacterium tuberculosis Direct test and Roche Amplicor Mycobacterium tuberculosis test. J Clin Microbiol 33, 1856-1859.

WHO (2002). Stop TB Annual Report 2001. http://www.stoptb.org/ material/Final_report2001.pdf

Wilson, S. M., al-Suwaidi, Z., McNerney, R., Porter, J. \& Drobniewski, F. (1997). Evaluation of a new rapid bacteriophage-based method for the drug susceptibility testing of Mycobacterium tuberculosis. Nat Med 3, 465-468.

Yuen, L. K., Ross, B. C., Jackson, K. M. \& Dwyer, B. (1993). Characterization of Mycobacterium tuberculosis strains from Vietnamese patients by Southern blot hybridization. J Clin Microbiol 31, 1615-1618. 